\title{
A Coaching Skills and Strategies Managers Utilize for Employee Improvement and Retention
}

\section{Dr. Bob Barrett ${ }^{\mathrm{a}}$}

${ }^{a}$ American Public University, School of Business, Charles Town, WV, United States, email: docjob00@msn.com.

\begin{abstract}
While managers and supervisors may be hired for certain variety of skills sets, abilities, and knowledge, not all of these workers may be educated or trained to be workplace coaches or mentors may or may not have the tolerance and patience for such a role. However, Human Resource Management professionals in the workplace need to realize that there may be a need for coaching training and skills enhancement workshops to prepare today's workforce managers. The key for success in this area is to conduct a need assessment for the workers and managerial staff to determine what is needed from today's workplace coaches in terms of needed skills sets and strategies to be utilized by them to help enhance, motivate, monitor, and evaluate the human capital working for today's organization. Next, the development and design of a coaching program can be instrumental in moving today's managerial workforce from general coaches to more specialized coaches to help develop and today's workforce, as well as help strengthen their own skills sets and knowledge in order to help obtain better results of organizational goals, as well as develop stronger working relationships and bonding with the workers. Equally important, today's workers need to exert an equal amount of effort and participation in a coaching environment in order to gain better outcomes in terms of performance and efficiency. This presentation will focus on the creation of better coaching programs and evaluation of coaching relationships and outcomes.
\end{abstract}

Keywords: Coaching, human resource management, human capital, workforce improvement, training. 


\section{Introduction}

Most organizations conduct some form of employee performance evaluation and offer feedback to help employees realize their strengths and weaknesses. However, there are organizations that are more proactive and offer some additional feedback in the form of coaching or mentoring employees in areas that they need improvement, as well as helping them to realize their potential. While managers and supervisors may be hired for certain variety of skills sets, abilities, and knowledge, not all of these workers may be educated or trained to be workplace coaches or mentors, and some may or may not have the tolerance and patience for such a role. However, Human Resource Management professionals in the workplace need to realize that there may be a need for coaching training, mentoring skills, and skills enhancement workshops to prepare today's workforce managers to help work with their assigned employees. In fact, one of the most rapidly growing forms of training in today's workplaces and educational institutions is done via online learning.

In 2016, a study was completed by Babson in which they found that one out of every three American university and college students were taken one or more online learning courses. They found tht some of the reasons for taking online courses versus traditional Face-toFace (F2F) classes ranged from time/scheduling issues, work and family issues, and the use of many new technologies in the adult learning environment, as well as training environments in today's organizations and corporatinons. Consequently, today's online manager, educators, and supervisors have to learn and share new forms of technology and applications in order to help students complete all needed learning objectives and gain valuable content knowledge. (Allen, 2013) Thus, there has been an increase in the focus on how employers can invest more training dollors and time in developing their employees with the use of online learning, as opposed to the traditional method of face-to-face learning. One of the downfalls of having face-to-face learning is that the employee is required to be away from their assigned work area and duties to participated in required training (even during peak times and essential times for their mere presence in the workplace can be vital to the success of helping their team and manager to accomplish organization goals and objectives). Barbara Smith (2000), chief learning officer for Burson-Marsteller stated that "If we don't have the best people creating the best product, we can't compete. What I'm after is creating the best people in the industry. E-learning is an option that provides us with real competitive edge - it helps us maximize our intellectual capital" (para. 2). However, one of the biggest problems in training in any environment, whether the workplace or learning environment, is the cloing of bad or inadequate training.

While training is seen as the "cure all" for training deficiencies or helping employees to gain additional skills and techniquest, there may be some shortfalls in some training that training designers need to consider. Thus, some organizations may use the "cookie-cutter" approach to training. Consequently, these training programs may have withered too 
quickly and inefficiently in terms of their initial intent for learning or training. In fact, some of the training quality of these programs has been diminished by the planning of the training design, as well as the repetitive overlay of the "cookie-cutter" approach of previous training programs which may have some deficiencies and poor design. While these programs may distribute end-of-course surveys to find out what participants liked or disliked, this does not mean that the responses have been read and acted upon. However, when does the organization and the employees start to be successful as a result of such lack of care in design and development of such "ill-prepared" training projects, workshops or seminars? For the purposes of this paper, the key focus will be on training and preparing coaching and mentoring candidates to assist employees in the workplace. As many organizations have started to focus on the role and function of intellectual capital, as well as the creation of knowledge management, one can see a trend with various organizations in terms of creating and maintaining learning organizations to provide better training, as well as capturing lessons learned and best practices to add to the organizations' own form of knowledge management. One way that they have been able to develop their own learning organization, as noted by Senge (1990, as noted in Barrett, 1999), is to look at changing their mindset and focus on what they do well or could do better. One of the key areas that many organizations have realized a need for change is their use of performance evaluation instruments and feedback meetings (SHRM, 2018).

Thus, if we look at the literature focused on the concept of learning organizations in the workplace, we can see that there are different trends or approaches used. Specifically, Sokolowska (2006) wrote that "if we look at learning organizations we can see two types of trends. She stated that "such organizations are understood in dynamic organizational categories that are oriented at their development, searches for new chances on the market and continually increases their effectiveness, efficiency and flexibility. The second group of learning organizations consists of such entities that choose growth through development of their employees." (Sokolewska, 2006). Consequently, more organizations, corporations, and educational institutions are creating these new types of specific learning communities with similar interests and practices, as well as increasing their own knowledge base and sharing some of their best practices. Thus, this has opened up a common goal of various stakeholders and organizations to learn from each other and nurture more networking opportunities. This has helped to increase more use of ever-changingtechnology and enable more managers and training designers to learn about common business and training practices. In retrosopect, many companies and organizations have seen a decrease in the workforce as more Baby Boomers are retiring; thus, this has presented more of a struggle for many employers retain qualified human capital and seek additional qualified candidates to fill their open positions. In the next section of this paper, an overview of online learning as a new form of training in today's workplaces. 


\section{Impact of Online Learning Technology in the Workplace}

Due to the shrinking workforce, as noted in the previous section, more companies and organizations are competing for market shares, as well as trying to attract and retain more qualified workers. Also, they have realized that investment in their human capital is a necessity, rather than just a luxury. However, due to economic and technological factors, many of these organizations have had to rethink their way of strategic planning and management of their operations. It should be noted that the use of "best practices" from others within their industry has helped them to remain competitive and move forward productively. Furthermore, as a result of the newer technologic approaches and training applications, many organizations are realizing the need to update, innovate, and rejuvenate their training program, especially for designing coaching and mentoring programs as another form of employee reinforcement and feedback in response to managers and employees wanting reinforcement assistance after assessing some employees in terms of their performance in the workplace. InCaS (2010) noted that "As a result of constant changes caused by globalisation, emerging technologies and shorter product life-cycles, knowledge and innovation have already become the main competitive advantages of many companies. Especially European small and medium-sized enterprises (SME) are highly dependent on the ability to identify changes in their global economic environment quickly and respond to these changes with suitable solutions." (European ICS Guideline, n.d.) Consequently, even like their European counterparts, American companies have had to scan their environments and strategically plan to focus on responding to potential changes in their environment, such as the workplace, in order to capture and maintain their market share and prepare for the future. Thus, one has to wonder whether we are better off today than before in terms of developing our intellectual capital, as well as our human capital, meaning the workforce? Also, we need to ponder whether or not if the onset of technological advancements has really helped or hindered our learning and knowledge building process? At this point of our discussion, let us look further at what is consider to be our human capital in the workplace and why organizations need to offer more value to the workforce in consideration for their contribution to the goals of their organization.

Historically speaking, many organizations have referred to individuals of their workforce as workers or employees. However, this has changed in order to "get with the times", traditional terminology of many element of today's workplaces has changed. Since some words like computers and data entry have been replaced with newer terms, such as laptops or mobile computers, as well as input for the entry of data, we have seen a change in terms dealing with human resources overall. For example, the people in charge of recruiting new candidates used to be called recruiters, but now they are referred to as Talent Managers. Consequently, the basic term "employee" is now called "human capital." Thus, one can explain human capital as "the capabilities of the company's employees necessary to provide 
solutions to customers, to innovate and to renew. In additional in individual capabilities, human capital includes the dynamics of an intelligent (learning) organization in a changing competitive environment, its creativity, and innovativeness" (Stewart, 1997) Consequently, one can see changes in how more and more trainers and educational learning providers have been investing more monies and time in developing their employees and adult learners with additional training and developments. Finally, there has been a growing need for training, there has been a bigger need for more standards and how training is used for various stakeholders (Freifield, 2012). Thus, how can one really know what type of training or follow-up work is needed for today's human capital and learners? It should be noted that the key for success in this area is to conduct a need assessment for the workers and managerial staff to determine what is needed from today's workplace coaches in terms of needed skills sets and strategies to be utilized by them to help enhance, motivate, monitor, and evaluate the human capital working for today's organization. In the following section, we will look at today's learning environments and how the proper strategic planning and management of the learning activities can help or hinder performance.

\section{The Impact of Technology in Learning Environments}

While educational reform has started to make changes in the classroom, along with the many technological improvements and changes to learning in general. Trainers have started to see instructional methods moving from a sheet of paper to the computer screen. The role and function of these trainers has changed with the introduction and placement of personal computers in the classroom. As more technology has entered into the workplace, the HR and training departmental professionals have started to find that computers had many different qualities and technological/training applications. Nonetheless, in light of these many technological advances, organizations have had to face the growing problems of poor planning and constraining budgets, which caused the decline of training in many companies. As a result, many employees developed trust issues with their employer demanding better performance from them, as noted on some of their performance evaluations, but they were given little or no training opportunities to help rectify performance issues. As a result, the growing level of mistrust has been another element that Human Resource professionals have had to work with managers and trainers to help employees overcome such trust issues. Therefore, it is important or organizational decision-makers and trainers, as well as HR professionals, to focus on establishing and nurturing trust early on with the learning process, it can help all stakeholders involved in a learning organization to move forward rather than "freezing" or "unfreezing" during critical moments in their development, as noted by Lewin (Kaminski, 2011). Nonetheless, not all trainers and/or managers are willing to spend additional time and resources for trust, but later learn the importance of this key strategic element. We can see that the concept of trust 
has many meanings, but for this paper there will be a focus on trust in the context of swift trust. In 2010, ChangingMinds.org concentrated on swift trust and how it affects certain groups and organizations. They stated that "Sometimes there is no time to build a trusting relationship, such as when group of people are thrown together and must start work immediately" (para. 4). Furthermore, as people are thrown together into a temporary setting, they may quickly organize and develop a temporary system in order to function as a group and meet their immediate needs (i.e., job duties, tasks, etc.). While some workplace training classes may be large and/or have a variety of employees working in various work environments with barriers, the use of online learning has helped to change some of these learning impediments and help to encourage more people to return back to education.

\section{Creating Better Strategic Learning Designs for Coaching and Mentoring}

Next, the development and design of a coaching program can be instrumental in moving today's managerial workforce from general coaches to more specialized coaches to help develop and today's workforce, as well as help strengthen their own skills sets and knowledge in order to help obtain better results of organizational goals, as well as develop stronger working relationships and bonding with the workers. Thus, we need to consider whether today's trainers and designers can find innovate ways to motivate employees and potential coaching and mentoring candidates. In fact, a trainer's key goal is to teach the course content, as well as to motivate the employee along the way to want to discover and inquire more on their own? Therefore, if an trainer wants to capture the same momentum from the live classroom setting into the world of online learning, there are several areas to consider, as noted below. Also, during the instructional period, the trainer needs to determine the level and extent that all learners/participants to achieve and master the designaed learning objectives. One way that online instructors can help changed the level of learning, quality of instructions, and adapting the course material for all types of learning styles is by assisting with the creating and design of the learning course. It should be noted that not all online schools permit instructors to design and develop courses, but many do encourage the use of additional teaching and learning materials. Finally, selected assessment activities of student learning can be done in terms of live chats, discussion threads, assignments, quizzes/exams, and/or projects. In order to consider such items within a course design, one needs to look at key areas to incorporate each of these items. 


\section{The Impact of Teaching Strategies, Tools, and Techniques}

It should be noted that not all teaching tools work or apply in all given learning environments. However, as some teaching tools may be viewed effective in one learning environment, they may not be as successful in another type of learning situation. Therefore, since each environment is unique, the trainer needs to assess the online environment and determine if change in training is necessary and current for today's workforce. However, we need to consider if trainers and training designers need to incorporate different teaching strategies and techniques to meet the ever-changing needs of these virtual learners in terms of learning from their cultural differences in order to enhance the learning experiences of all? Further, can these professionals address the changing learning needs of all adult learners, especially people with disabilities? Consequently, this new type of learning environment has helped to break down a few of the barriers as previously discussed in this paper. Also, this new type of learning environment has helped to "level" the playing field, in which students can act, react, and be proactive in the learning process. White (2002) noted "Nowhere is thinking more evident than in the textual environment of the online classroom. If writing is thinking, then online students display their thinking throughout the course, illustrating their individual styles and changing attitudes" (p. 6). Consequently, trainers and designers can incorporate various strategies to help draw upon the experiences of all class members - rather than just a select few. This helps to demonstrate the beauty of online learning - because online learning is a continuous process (not limited to a set time and place as a traditional course is scheduled). As we look at the various evolutionary steps of technology in today's learning environment, we can see how it has influenced the diminishing workforce. If we look at the impact of changes in the workplace, we can see some results of such impact. Equally important, today's workers need to exert an equal amount of effort and participation in a coaching environment in order to gain better outcomes in terms of performance and efficiency. This presentation will focus on the creation of better coaching programs and evaluation of coaching relationships and outcomes. The next section will overview a potential training program for today's workplace trainers and designers in creating and implementing an online training program for potential candidates to become workplace coaches and mentors to help employees with areas for performance improvements. 


\section{Training Program and Strategies for Online Instructor}

The following section outlines a typical training program for online instructors.

- $\quad$ Module 1 - Teaching and Learning of Employees

In this module, candidates learn about the various communications tools used in the online learning environment. Potential coaches/mentors examine and discuss how adults learn. Also, they explore how teach and learning are connected.

- $\quad$ Module 2 - Teaching Strategies for Coaching/Mentoring Success

During this module, students learn the important of time management and how to effectively plan their teaching schedules. A key focus is on team facilitation and conflict management strategies. While we hope that all learning experiences are positive, trainers need to know how to handle conflicts that may occur - especially with employees who may not see the need for any form of coaching or mentoring.

- $\quad$ Module 3 - Helping Students to Think Critically

In this module, students will look at Bloom's Taxonomy and how it is used in course design and curricula. There is a key discussion on the connections between teaching and learning theories. Finally, trainers will discuss how critical thinking is used in the classroom.

- $\quad$ Module 4 - Providing Feedback

During this module, potential coaches/mentors will look at sample student work and critique it with the use of a standard rubric. They will focus on various criteria, as well as applying comments on APA style and format. Also, there will be a variety of role-playing activities and online applications to be shared with future mentees.

- $\quad$ Module 5 - Ethical Issues

Why is confidentiality important in the coaching and mentoring environment? Students will look at the various problems and issues associated with coaching and mentoring assignments.

- Module 6 - Workplace Policies and Procedures

During this final module, students will learn more about their role and function as a coach and/or mentor in the workplace. A key discussion will be held on the workplace's mission and how it reflects the organization's culture. 
Upon completion of these modules, the course trainer will prepare an evaluation form for each enrolled coaching/mentoring candidate.

\section{Conclusion}

While this paper has covered the key changes in the workplace environment in terms of changing technology, shrinking workforce, and need for more qualified or improved works, it has also overviewed the need to train potential workplace coaches and mentors to help employees improve upon designed performance issues. As many companies return back to the importance of training and education by adding more time and resources to training budgets, many entities are rethinking and re-evaluating the use of their funds to help support their employees professional and career development. While organizations examine what works and does not function well for them and their organization as a whole, they are starting to realize that the investment in their human capital is a win-win situation for all stakeholders.

\section{References}

Allen, as noted in Babson Survey Research Group. 2013 US Survey of Online Learning Published. Retrieved http://www.icde.org/2013+US +Survey+of+Online+Learning +published.b7C_wRjQXf.ips, (2013).

Babson Survey Research Group (2013). 2013 US Survey of Online Learning Published. Retrieved http://www.icde.org/2013+US +Survey+of+Online+Learning+published .b7C_wRjQXf.ips.

Barrett, B. (1999). Best Disability Employment Practices: A Case Study. The George Washington University (Doctoral Dissertation).

Changing Minds (2011). Retrieved on October 1, 2011 from http://changingminds.org/disciplines/change management/lewin change/lewin change. html.

European ICS Guideline (n.d.). http://www.inthekzone.com/pdfs/Intellectual_Capital_Statement.pdf. Retrieved Dec. 15, 2010.

Freifield, L. (2012). Investing in a New Workforce Training and Education Program. Training. Retrieved from https://trainingmag.com/content/investing-new-workforcetraining-and-education-program.

Kaminski, J. (2011). Theory applied to informatics: Lewin's change theory. Canadian Journal of Informatics, 6 (1). 
Senge, P. (1990). The Fifth Discipline: The art and practice of the learning organization, Doubleday, New York.

Smith, B. (2000), chief learning officer for Burson-Marsteller stated that "If we don't have the best people creating the best product, we can't compete.

Society of Human Resource Management (2018). Retrieved from www.shrm.org.

Sokolewska, O. (2006). E-learning w szkoleniu kadr - raport z badań. Zarządzanie zasobami ludzkimi, 3-4 (48-49) 100-108.

Stewart, (1997). Intellectual Capital. New York: Doubleday Currency. pp. 62-63. 